\title{
1 VolcFlow capabilities and potential development for the simulation of lava
}

2 flows

3 Karim KELFOUN*, Silvia VALLEJO VARGAS

4 1. Laboratoire Magmas et Volcans, Université Blaise Pascal - CNRS - IRD, OPGC, 5 rue $5 \quad$ Kessler, 63038 Clermont Ferrand

2. Instituto Geofisico, Escuela Politécnica Nacional, Ladrón de Guevara E11-253 y

7 Andalucía, Aptdo 2759, Quito, Ecuador

$8 *$ corresponding author (e-mail: k.kelfoun@ opgc.univ_bpclermont.fr)

Abstract: VolcFlow is a finite difference Eulerian code based on the depth-averaged approach and developed for the simulation of isothermal geophysical flows. Its capability for reproducing lava flows is tested here for the first time. The field example chosen is the 2010 lava flow of Tungurahua volcano (Ecuador), whose emplacement is tracked by projecting thermal images onto a georeferenced digital topography. Results show that, at least for this case study, the isothermal approach of VolcFlow is able to simulate the velocity of the lava through time, and the extent of the solidified lava. However, the good fit between the modelled and the natural flow may be explained by the short emplacement time ( 20 hours) of a thick lava $(\sim 5 \mathrm{~m})$, which could limit the influence of cooling on the flow dynamics, thus favouring the use of an isothermal rheology. 
Lava flows exhibit complex rheologies, which vary in time and space and control their emplacement. Numerical models simplify their physics, to a greater or lesser extent, in an attempt to predict their evolution and the areas impacted. Some approaches are simply based on trajectory estimation from topographic analysis, adding probabilistic or stochastic variations of the trajectories to calculate a flow width (DOWNFLOW, Favalli et al. 2005; VORIS, Felpeto et al. 2007). The runout of the lava flow cannot be simulated. Other approaches are in 2D, using a thickness below which the lava cannot flow and above which it is distributed to the neighbouring cells. This thickness is dependent on the topographic slope (FLOWFRONT, Wadge et al. 1994) or on the lava temperature (SCIARA, Crisci et al. 2004) but dynamics are not included in the model. Ishihara et al. (1990) and Miyamoto and Sasaki (1998) use fluid dynamics and cooling equations to calculate the lava spreading in 2D (runout and width) on an incline. FLOWGO (Harris and Rowland 2001) estimates the lava trajectory based on similar dynamics and cooling equations on a realistic topography, the lava width being calculated from volume conservation. The equations of mass, momentum and thermal balances have also been solved in 2D (runout and width) using a depth-averaged approach (no variation of the properties vertically or at right angles to the ground) on a realistic topography, the rheology of the lava being related to its cooling (Costa and Macedonio 2005). LavaSIM (Hidaka et al. 2005) uses similar equations to simulate the lava flow but it solves them in 3D. This allows a vertical structure to be calculated with a crust and a fluid core. A more detailed review of existing models can be found in Hidaka et al. (2005). The smoothed particle hydrodynamics is a promising approach that is starting to be applied to lava flow simulation (e.g. Hérault et al. 2011).

For hazard assessment, observatories and public authorities need user-friendly tools to predict the emplacement of the lava both sufficiently accurately and relatively rapidly. Some models are not available, others are too simple to be used for hazard assessment, while the more 
complex models require powerful computing resources and calculation times which are longer than the emplacement times of real flows (e.g. Hidaka et al. 2005). The numerical code, VolcFlow, has been created for the simulation of geophysical flows within a few hours using a desktop computer. It has been applied successfully to the simulation of debris avalanches, dense pyroclastic flows and tsunamis generated by landslides (Kelfoun and Druitt 2005; Kelfoun et al. 2008; Kelfoun et al. 2009; Kelfoun et al. 2010; Giachetti et al. 2011; Charbonnier et al. 2013). The aim of this chapter is to present the VolcFlow code, which is used in two other chapters of this book, and to discuss its limitations and possible evolution for the simulation of lava flows. We show that the simple isothermal approach of VolcFlow can accurately reproduce - at least for the case studied - the lava flow emplacement.

\section{Model}

VolcFlow uses a topography-linked coordinate system, with $x$ and $y$ parallel to the local ground surface. The flow is simulated by a depth-averaged approach that solves mass (eq. 1) and momentum (eqs. 2, 3) balance equations:

$$
\frac{\partial h}{d t}+\frac{\partial}{\partial x}(h u)+\frac{\partial}{\partial y}(h v)=\frac{\partial h_{s}}{d t}
$$

$$
\frac{\partial}{\partial t}(h u)+\frac{\partial}{\partial x}\left(h u^{2}\right)+\frac{\partial}{\partial y}(h u v)=g h \sin \alpha_{x}-\frac{1}{2} \frac{\partial}{\partial x}\left(g h^{2} \cos \alpha\right)+\frac{\tau_{x}}{\rho}
$$

$$
\frac{\partial}{\partial t}(h v)+\frac{\partial}{\partial x}(h v u)+\frac{\partial}{\partial y}\left(h v^{2}\right)=g h \sin \alpha_{y}-\frac{1}{2} \frac{\partial}{\partial y}\left(g h^{2} \cos \alpha\right)+\frac{\tau_{y}}{\rho}
$$

The variable $h$ is the flow thickness, perpendicular to the topography, $\mathbf{u}=(u, v)$ is the flow velocity, $\alpha$ is the ground slope, $\tau=\left(\tau_{x}, \tau_{y}\right)$ is the retarding stress, $\rho$ is the bulk density of the lava flow and the subscripts denote components in the $x$ and $y$ directions. The approach is 
similar to the model of Costa and Macedonio (2005), except that VolcFlow does not incorporate an equation of thermal balance, nor is cooling calculated.

Equation (1) means that the thickness, $h$, of the lava at a given area varies with time depending on the lava flux that enters or leaves the area $\left(2^{\text {nd }}\right.$ and $3^{\text {rd }}$ terms $)$ or on the lava flux at the vent, $\frac{\partial h_{s}}{d t}$ (this term equals 0 elsewhere). Equations (2) and (3) calculate the momentum variations, and thus the velocity of the lava, related to lava flux ( $2^{\text {nd }}$ and $3^{\text {rd }}$ terms) and the stresses exerted ( $4^{\text {th }}$ to $6^{\text {th }}$ term). No "vent" term is included in the momentum equations because we have assumed in the following that the lava is emitted with no velocity along $x$ and $y$. VolcFlow allows the user to define constant or time-dependent effusions rates, several eruptive sources, as well as the locations and the geometries of the sources.

The retarding stress, $\tau$, varies depending on the rheology chosen. The advantage of VolcFlow is that it can solve several types of rheological equations: frictional, viscous, plastic, etc. It can also solve other more complex user-defined rheological laws (e.g. Davies et al. 2010). A fully molten lava exhibits a Newtonian rheology (Gonnermann and Manga 2007). However crystallization of lava by cooling and degassing changes this behaviour (e.g., Pinkerton and Sparks 1978; Cimarelli et al. 2011; Lev et al. 2012). The lava then requires a minimal shear stress in order to flow. The Bingham law is the simplest approximation of the behaviour of threshold fluids: a Bingham body remains at rest while the applied shear stresses (caused by lava weight, for instance) are less than the yield strength $\tau_{0}$. Once the yield strength is overcome, the body flows with a flow velocity that depends on its viscosity, thickness and yield strength. The latter allows the effect of the resistant crust that stops the flow when it becomes too thin to be simulated. The resisting stress exerted by a Bingham flow is given by:

$$
\tau=\tau_{0}+\eta \frac{d u}{d h}
$$


where $\eta$ is the dynamic viscosity (in Pa s). Rewritten in a depth-averaged form compatible with equations (2) and (3), equation (4) becomes:

$$
\tau_{x}=\tau_{0} \frac{u_{x}}{\|\mathbf{u}\|}+3 \eta \frac{u_{x}}{h} \text { and } \tau_{y}=\tau_{0} \frac{u_{y}}{\|\mathbf{u}\|}+3 \eta \frac{u_{y}}{h}
$$

The equations are solved using a shock-capturing numerical method based on a double upwind Eulerian scheme. The method, and some tests done to ensure the quality of VolcFlow using various rheologies, are presented in Kelfoun and Druitt (2005). Another test of the capability of VolcFlow to reproduce analytical solutions for viscous rheology is presented in this book by Cordonnier et al. (2015). VolcFlow runs in the Matlab ${ }^{\circledR}$ environment and benefits from its powerful programming capacities for complex scenario definition (topography, source geometry, rates, etc.), the post treatment of the results, and the graphical output. The code and some examples of simulation can be found on the VolcFlow webpage.

\section{Application to a lava flow of Tungurahua volcano}

The eruption of December 4-5, 2010

Tungurahua stratovolcano (5023 m a.s.1.) is located in the Eastern Cordillera of Ecuador, and is one of the most active volcanoes in the country (Hall et al. 1999; Le Pennec et al. 2008). It is andesitic in composition (58-59 wt\% $\mathrm{SiO}_{2}$, Samaniego et al. 2011). The present activity, which began in 1999, is characterized by vulcanian, strombolian and subplinian explosions (Steffke et al. 2010; Samaniego et al. 2011), generating a variety of volcanic products from the single vent located in the summit crater. In this study we focus on the paroxysm of the November - December phase of 2010, which took place on December 4. The eruption started at $13 \mathrm{~h} 50$ UTC (= local time +5$)$. It initiated a strong explosive phase, which continued for $\sim 5$ 
hours, with a high eruptive ash column that rose about $4 \mathrm{~km}$ a.s.l., accompanied by the generation of $\sim 34$ pyroclastic density currents that flowed down gullies to the northeast, northwest, west and southwest of the volcano. At about $22 \mathrm{~h} 40$ UTC on December 4 a new pulse of activity began, related to a harmonic tremor signal which was recorded for $\sim 2.5$ hours by all the volcano's seismic stations. Thanks to the favourable weather conditions, scientists at the Tungurahua Volcano Observatory (OVT, $13 \mathrm{~km} \mathrm{NW}$ of the summit) were able to observe the emission of a lava flow, flowing out of the summit crater and descending the upper part of the NW flank of the volcano (Weekly reports, OVT-IG, www.ig.epn.edu.ec, Vallejo et al. 2012). The lava flow emplacement was recorded by a thermal camera FLIR, model PM 695, from the OVT, between December 4-6. Around 90 thermal images of the lava flow were taken. Lava overflowed for a period of 5 hours and traveled for about $1.8 \mathrm{~km}$ over 20 hours with a velocity that decreased progressively with time from a maximal initial value of about $200 \mathrm{~m} / \mathrm{h}$ (Fig. 3). The thickness of the lava was estimated visually and from topography analysis to be about 3 to 5 meters, and its volume about $10^{6} \mathrm{~m}^{3}$.

\section{Measurement of the lava emplacement}

To check the capability of numerical models to reproduce the emplacement of a lava flow, the extension predicted by a model is often compared with the natural extension once the lava comes to rest. However, the model also needs to be checked dynamically to evaluate the adequacy of the model chosen. To follow the evolution of the lava with time we have developed an original photogrammetric approach. After having calculated the position and the orientation of the thermal camera, and the characteristics of the lens, we can calculate the equation of the line that passes through the image of a studied object $\left(\mathrm{P}_{1}\right.$ on Fig. 2$)$ on the camera sensor and the centre of perspective of the camera ( $\mathrm{C}$ on Fig.2). The real position in 
space of the object $\left(\mathrm{P}_{2}\right)$, if it lies on the ground, is located at the intersection between this line and the topography. Each pixel of the lava flow can then be located on the volcano (Fig. 2). The resolution of the thermal camera is relatively low $(320 \times 240)$ and the precision of the lava front location on the volcano ranges between 40-65 m depending on the topographic slope and the distance from the camera. The error is represented on Fig. 3 and is small relative to the $1.8 \mathrm{~km}$ extension of the lava.

\section{Simulation of the lava flow}

The Digital Elevation Model (DEM) used for the simulation was calculated within the framework of the SIGTIERRAS project of the Ecuadorian government, in 2011, some months after the eruption took place. The DEM resolution is $4 \mathrm{~m}$. The 2010 lava is visible on the digital topography and has been removed from the DEM by extrapolating the surrounding topography. The lava is simulated by a constant flux escaping from the lower part of the rim of the summit crater. We assume a constant rate of lava production of about $55.5 \mathrm{~m}^{3} / \mathrm{s} \mathrm{in} \mathrm{order}$ to erupt a volume of $10^{6} \mathrm{~m}^{3}$ in 5 hours. The density is fixed at $2200 \mathrm{~kg} / \mathrm{m}^{3}$.

Figure 3 shows a comparison between the position of the lava front with time based on the observation (dots) and the model (lines). 90 thermal images were taken during the eruption but we have used the 10 best images where the lava front can be located unambiguously. The best-fit is obtained for a viscosity of $\eta=4 \times 10^{6} \mathrm{~Pa}$ s and a yield strength of $\tau_{0}=60 \mathrm{kPa}$ (black thick solid line). The position of the lava front with time is reproduced by the model with an error of less than $50 \mathrm{~m}$, apart from the first dot $(<100 \mathrm{~m})$. The distance reached by the front at rest is simulated accurately $(<10 \mathrm{~m})$ even if the lava front is located $100 \mathrm{~m}$ to the east of the real front (Fig. 3B), due to small variations in the topography that are not captured by the DEM used. The flow front velocity, the time lava stopped moving and the thickness of the 
model are all also compatible with the observations (Fig. 3A and B). The area covered by the simulated lava is generally compatible with reality but differs of about $100 \mathrm{~m}$ close to the lava front and in the middle of the southwest edge (Fig. 3B).

To illustrate the sensitivity of the model to the rheological parameters used, Figure 3 also shows curves obtained by varying one of the parameters from the best-fit simulation. The viscosity influences the velocity of the flow (e.g. $\eta=5 \times 10^{6} \mathrm{~Pa}$ s) while the value of $\tau_{0}$ controls the thickness and consequently the runout of the lava (e.g. $\tau_{0}=50 \mathrm{kPa}$ and $\tau_{0}=70 \mathrm{kPa}$ ). A change in $\tau_{0}$ of $10 \mathrm{kPa}$ changes the runout by approximately $200 \mathrm{~m}(\sim 12.5 \%)$.

A critical point for the simulation of some lava flows is the dependence of the results on the DEM resolution. Changing the resolution can slightly change the shape and position of the source. But the main problem comes from the flow capability of natural lavas and models, which is related to lava thickness: for the same lava, a thick flow can move even on a horizontal surface, while a thin flow can come to a stop even on steep slopes. With a low resolution DEM, the small-scale topography that can influence lava emplacement is not reproduced precisely: the simulated flows can spread out more or less than in reality. If the width changes, the thickness changes too and, consequently, the distance reached by the front. Figure 3 shows results obtained with the parameters of the best-fit model on DEMs with resolutions of $8 \mathrm{~m}$ and $16 \mathrm{~m}$. The resolution has a small influence on the emplacement for the initial $1200 \mathrm{~m}$, but affects the final position of the front by up to $200 \mathrm{~m}$ (Fig. 3). Previous tests have shown that the simulation accuracy increases by improving DEM resolution up to a point where changes no longer have much influence on the flow length. Since we detect a large difference between the simulations carried out at resolutions of $4 \mathrm{~m}$ and $8 \mathrm{~m}$, we cannot assert that our best-fit model gives the accurate value of the yield strength $\tau_{0}$, and an error of +/- $10 \mathrm{kPa}$ is possible. The strong influence of the resolution change for the lava simulated 
here is due to its being channelled into a narrow valley downstream: wide, thick flows are less influence by small variations in topography than thin, narrow flows.

\section{Capabilities of the model and future evolutions}

The example of the December 4, 2010 lava flow of Tungurahua shows that a simple isothermal approach can be used for simulating some lava flow emplacements. VolcFlow, which is freely distributed and runs on a desktop computer, could be a useful tool for hazard assessments related to lava flows. Each simulation needs about 3 hours of computation time on one $2.6 \mathrm{GHz}$ processor of a desktop computer for the highest resolution $(4 \mathrm{~m})$ and a calculation domain of $601 \times 501$ meshes ( $\sim 30$ mins with an $8 \mathrm{~m}$ resolution, $<2$ mins with a $16 \mathrm{~m}$ resolution).

However, it should be stressed that the lava studied was emplaced during a relatively short period of time (about 20 hours) and was relatively thick (3-5 m). Under these conditions, the effect of the cooling and the subsequent rheological changes is probably small, which explains how an isothermal model can reproduce the lava flow emplacement. Future studies need to be systematically conducted to explore the limits of this isothermal approach. There is a real need for quantified observations to objectively evaluate the quality of the different models available and the assumptions made.

Cooling and associated rheological changes could also be calculated by VolcFlow (as in the approach of Costa and Macedonio 2005). Indeed, an appealing feature of the code is that it is able to advect any volumetric or surface properties. It can then easily be evolved to take additional balance equations into account, for instance for thermal energy and crystallinity. The cooling and rheological changes of the flow could thus be calculated, as long as the physics operating in the flow is compatible with the depth-averaged assumptions. This is the 
principal limitation of VolcFlow: the depth-averaged approach cannot take into account complex 3D phenomena such as crust and tunnel formation, or decoupling between the crust and the hot internal lava.

The calculation time is currently a few hours, but this could easily be reduced to some tens of minutes by simplifying the numerical scheme. At present, VolcFlow uses a time-consuming numerical scheme to solve the momentum advection (equations 2 and 3) that was designed to be stable with fast, thin flows. Because lava flows are relatively slow, momentum equations are simpler to solve. Thus, if VolcFlow were to evolve further towards the simulation of lava flows, it could be simplified to speed up the calculation time.

Two other studies using VolcFlow for lava flow simulation are presented in the book: a benchmarking (Cordonnier et al., 2015) and a damage and evacuation assessment (Latutrie et al., in review).

\section{Acknowledgements}

We thank the Ecuadorian SENESCYT, the Instituto Geofisico of Quito (IG-EPN) and the Institut pour la Recherche et le Développement (IRD) for their support. This research was financed by the French Government Laboratory of Excellence initiative ${ }^{\circ}$ ANR-10-LABX0006, the Région Auvergne and the European Regional Development Fund.This is Laboratory of Excellence ClerVolc contribution number 135.

\section{Références}

Charbonnier, S. J., Germa, A., Connor, C.B., Gertisser, R., Preece, K., Komorowski, J.-C., Lavigne, F., Dixon, T. \& Connor, L. 2013. Evaluation of the impact of the 2010 pyroclastic density currents at Merapi volcano from high-resolution satellite imagery, field investigations and numerical simulations. Journal of Volcanology and Geothermal Research, 261, 295-315, 
Cimarelli, C., Costa, A., Mueller, S. \& Mader H. 2011. Rheology ofmagmas with bimodal crystal size and shape distributions: Insights from analogue experiments, Geochemistry, Geophysics, Geosystems, 12, Q07024, doi:10.1029/2011GC003606

Cordonnier, B., Lev, E., Garel, F. 2015. Benchmarking volcanic mass flow models. In: Harris, A., De Groeve, T., Garel, F., \& Carn, S.A. (eds) Detecting, Modelling and Responding to Effusive Eruptions. Geological Society, London, Special Publications, 426. First published online Month XX, 20XX, http://dx.doi.org/10.1144/SP426.XX.

Costa, A. \& Macedonio, G. 2005. Numerical simulation of lava flows based on depthaveraged equations, Geophysical Research Letters, 32, L05304, doi:10.1029/2004GL021817.

Crisci, G. M., Rongo, R., Di Gregorio, S. \& Spataro, W. 2004. The simulation model SCIARA: the 1991 and 2001 lava flows at Mount Etna. Journal of Volcanology and Geothermal Research, 132, 253-267, doi: 10.1016/S0377-0273(03)00349-4

Davies, T., McSaveney, M. \& Kelfoun, K. 2010. Runout of the Socompa volcanic debris avalanche, Chile: a mechanical explanation for low basal shear resistance. Bulletin of Volcanology 72 (8), doi 10.1007/s00445-010-0372-9.

Favalli, M., Pareschi, M. T., Neri, A. \& Isola, I. 2005. Forecasting lava flow paths by a stochastic approach, Geophysical Research Letters, 32, L03305, doi:10.1029/2004GL021718

Felpeto, A., Martí, J., Ortiz, R. 2007. Automatic GIS-based system for volcanic hazard assessment. Journal of Volcanology and Geothermal Research, 166, 106-116.

Giachetti, T., Paris, R., Kelfoun, K. \& Pérez-Torrado, F.J. 2011. Numerical modelling of the tsunami triggered by the Guìmar debris avalanche, Tenerife (Canary Islands): comparison with field-based data. Marine Geology, doi: 10.1016/j.margeo.2011.03.018

Gonnermann, H. \& Manga, M. 2007. The fluid mechanics inside a volcano, Annual Review of Fluid Mechanics, 39, 321-356.

Hall, M.A., Robin, C., Beate, B., Mothes, P. \& Monzier, M. 1999. Tungurahua Volcano, Ecuador: structure, eruptive history and hazards, Journal of Volcanology and Geothermal Research, 91, 1, 1-21, doi:10.1016/S0377-0273(99)00047-5

Harris, A.J.L. \& Rowland, S.K. 2001. FLOWGO: A kinematic thermo-rheological model for lava flowing in a channel, Bulletin of Volcanology, 63, 20-44.

Hérault, A., Bilotta, G., Vicari, A., Rustico, E. \& Del Negro, C. 2011. Numerical simulation of lava flow using a GPU SPH model, Annals of Geophysics, 54, 5, 2011; doi: 10.4401/ag5343.

Hidaka, M., Goto, A., Umino S. \& Fujita, E. 2005. VTFS project: Development of the lava flow simulation code LavaSIM with a model for three-dimensional convection, spreading, and solidification, Geochemistry, Geophysics, Geosystems, 6, Q07008, doi:10.1029/2004GC000869

Ishihara, K., Iguchi, M. \& Kamo K. 1990. Numerical simulation of lava flows on some volcanoes in Japan, in Lava Flows and Domes, IAVCEI Proc. Volcanol., 2, edited by J. Fink, pp. 174-207, Springer, New York.

Kelfoun, K., Druitt, T.H., van Wyk de Vries, B. \& Guilbaud, M.-N. 2008. Topographic reflection of Socompa debris avalanche, Chile. Bulletin of Volcanology, 70, 1169-1187, doi: 10.1007/s00445-008-0201-6

Kelfoun, K., Samaniego, P., Palacios, P. \& Barba, D. 2009. Testing the suitability of frictional behaviour for pyroclastic flow simulation by comparison with a well-constrained eruption at 
Tungurahua volcano (Ecuador). Bulletin of Volcanology, 71(9), 1057-1075, doi: 10.1007/s00445-009-0286-6

Kelfoun, K., Giachetti, T. \& Labazuy P. 2010. Landslide-generated tsunamis at Réunion Island, Journal of Geophysical Research B, 115, F04012, doi: 10.1029/2009JF001381

Kelfoun, K. \& Druitt, T.H. 2005. Numerical modelling of the emplacement of the 7500 BP Socompa rock avalanche, Chile. Journal of Geophysical Research, 110, B12202, doi: 10.1029/2005JB003758, 2005.

Latutrie B., Andredakis, I., De Groeve, T., Harris, A., Langlois, E., Van Wyk de Vries, B., Saubin, E., Bilotta, G., Cappello, A., Crisci, G., D'Ambrosio, D., Del Negro, C., Favalli, M., Fujita, E. \& Iovine, G. 2015. Testing a GIS for damage and evacuation assessment during an effusive crisis. In: Harris, A., De Groeve, T., Garel, F., \& Carn, S.A. (eds) Detecting, Modelling and Responding to Effusive Eruptions. Geological Society, London, Special Publications, 426. In Review.

Le Pennec, J.-L., Jaya, D., Samaniego, P., Ramón, P., Moreno Yánez, S., Egre, J. \& van der Plicht, J. 2008. The AD 1300-1700 eruptive periods at Tungurahua volcano, Ecuador, revealed by historical narratives, stratigraphy and radiocarbon dating, Journal of Volcanology and Geothermal Research, 176, 1, 70-81.

Lev, E., Spiegelman, M., Wysocki, R.J. \& Karson, J.A. 2012. Investigating lava flow rheology using video analysis and numerical flow models, Journal of Volcanology and Geothermal Research, 247-248, 62-73.

Miyamoto, H. \& Sasaki, S. 1998. Numerical simulations of flood basalt lava flows: Roles of parameters on lava flow morphologies, Journal Geophysical Research, 103(B11), 27,48927,502 .

Pinkerton, H. \& Sparks, R.S.J. 1978, Field measurements of the rheology of lava. Nature, 276, 383-385.

Samaniego, P., Le Penneca, J.-L., Robin, C. \& Hidalgo, S. 2011. Petrological analysis of the pre-eruptive magmatic process prior to the 2006 explosive eruptions at Tungurahua volcano (Ecuador), Journal of Volcanology and Geothermal Research, 199, 1-2, 69-84.

Steffke, A.M., Fee, D., Garces, M. \& Harris, A. 2010. Eruption chronologies, plume heights and eruption styles at Tungurahua Volcano: Integrating remote sensing techniques and infrasound. Journal of Volcanology and Geothermal Research, 193, 3-4, 143-160.

Wadge, G., Young, P.A.V. \& McKendrick, I.J. 1994. Mapping lava flow hazard using computer simulation, Journal Geophysical Research, 99, B1, 489-504. 
Fig. 1. Photographs of the northwest flank of Tungurahua volcano (Ecuador) and of the lava flow studied. This lava flow was emplaced on December 4, 2010 and is contoured with a red line (credit: B. Bernard, IG-EPN). The length of the lava flow is about $1600 \mathrm{~m}$ and the slope of the volcano varies from $\sim 40^{\circ}$ at the crater to $\sim 25^{\circ}$ at the front of the lava flow.

Fig. 2. The calculation of the position of the front and the extension of the lava flow through time is done by projecting the thermal images onto a 4m-digital topography.

Fig. 3. A. Time evolution of the distance between the lava front and the source (along the slope) during the eruption of December $4^{\text {th }}, 2010$ at Tungurahua volcano. The observations are shown by the red dots, and the best-fit model by the thick black line. Other lines are simulations done by varying one parameter of the best-fit simulation: yield strength, $\tau_{0}$, viscosity, $\eta$, or DEM resolution, $d x$. Error bars are estimated from the accuracy of the projection techniques. Distances are calculated along the slope, following the position of the front. B. X-Y view of the thermal image projected onto the topography. The red dots are the successive positions of the lava front with time, as shown on A. The real lava is in white and

333 yellow. The black line is the simulated lava. C. 3D-view of the simulated lava flow once it is 334 at rest. 




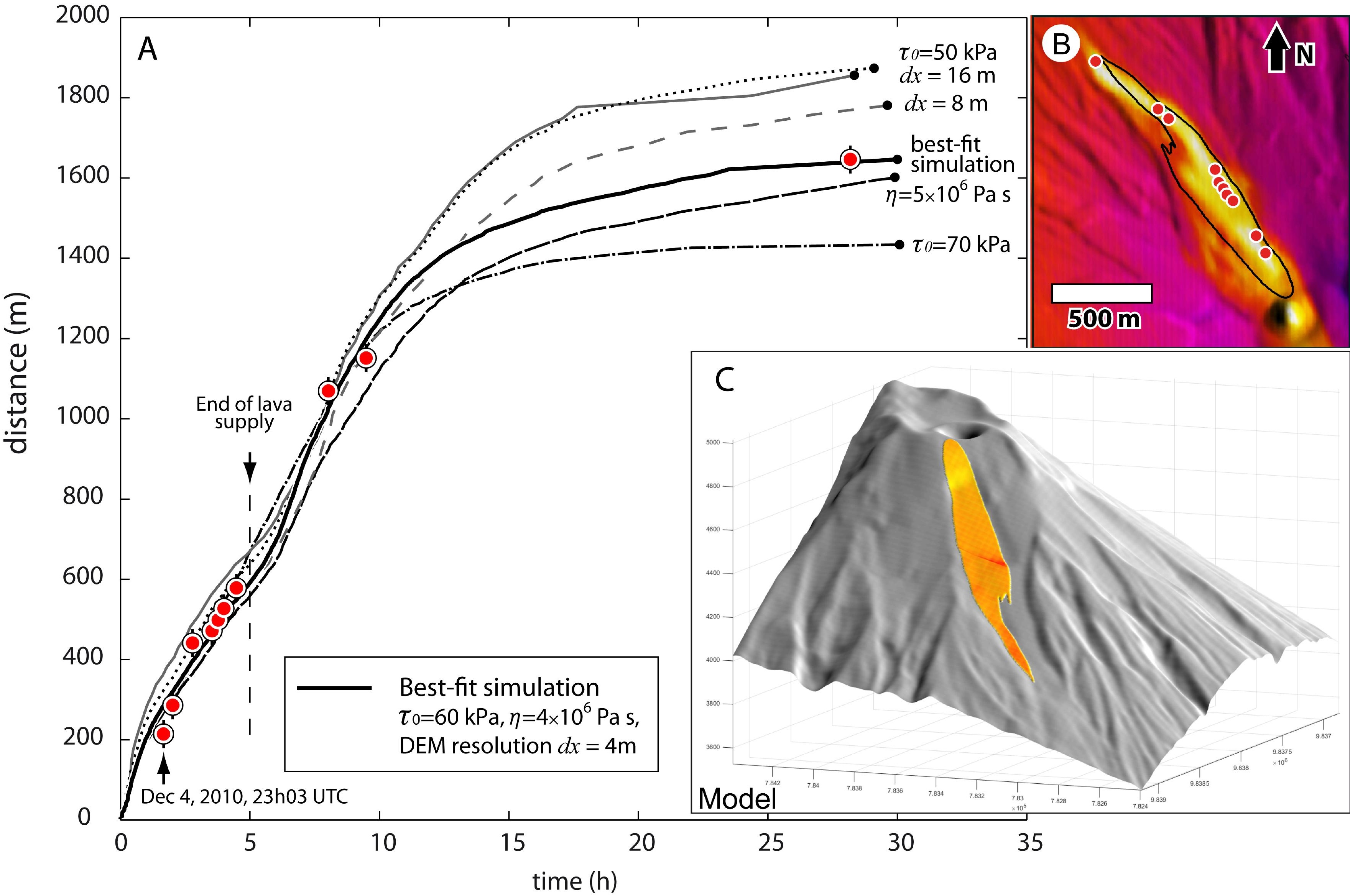

